\title{
Influence of a nonforage diet on plasma leptin in dairy goats throughout lactation
}

F. Rosi, L. Rapetti

Istituto di Zootecnia Generale, Facoltà di Agraria, Università di Milano, via Celoria 2, 20133 Milano, Italy

Introduction Leptin is a $16 \mathrm{kDa}$ peptide hormone mainly secreted by fat cells to regulate of food intake and energy homeostasis, and to signal the status of body energy stores to the brain (Houseknecht et al., 1998). In ruminant, reducing feedstuffs particle size increases DM intake, particularly if feedstuffs quality is poor, due to a shorter retention time of the particles in the rumen. By-products are included in the ration to supply energy and protein, but they have often a high content of fibre. The by-product fibre has different properties than forage NDF, being characterised by particles of small dimensions and a high density. The aim of this study was to compare the plasma level of leptin in lactating goats fed a traditional silage-based diet or a totally free forage diet, throughout lactation and during the pre and post-feeding state.

Materials and methods Eight second parity Saanen goats were assigned randomly to one of the two following dietary treatments: a silage-based forage diet with a forage to concentrate ratio of 55:45 (control, C) and a commercial nonforage diet (NF) containing 8.5\% of whole cottonseed. Each group of four goats was fed its own assigned diet throughout the entire lactation. There was a great difference between the two diets for DM and some important chemical components (DM: 46 vs 91\%; CP: 14.8 vs 21.4\%; EE: 3.2 vs 5.6\%; ADF: 17.8 vs 26.1\%; ADL:2.1 vs 9.6\%; NFC: 40.6 vs $28.8 \%$ on DM, for C and NF, respectively). The diets were offered for ad libitum intake twice daily. The trial was divided into three experimental periods of $8 \mathrm{~d}$ during early (40 DIM), mid (100 DIM) and late lactation (220 DIM). DMI was individually recorded daily during the three experimental periods. At the end of each period, blood samples were collected from each goat before the morning feeding and $4 \mathrm{~h}$ after feeding. Plasma leptin was determined by RIA (Linco Research Inc., St Charles, MO, USA). Data were statistically analysed using GLM Procedure of SAS (1996) with the repeated statement.

Results The lack of forages in NF diet did not affect body weight and milk production throughout lactation, but it significantly increased DMI (graph.); NF diet also reduced pre-feeding and post-feeding plasma leptin. These effects were more marked at early and mid lactation (table). Concerning the time-day effect, the post-feeding plasma leptin resulted higher than fasting leptin (3.22 vs $2.90 \mathrm{ng} / \mathrm{ml}, \mathrm{P}=0.004)$.

Table Pre- and post-feeding plasma leptin levels (ng/ml) and daily dry matter intake (DMI) throughout lactation (Least squares means) $(\mathrm{n}=8)$.

\begin{tabular}{|c|c|c|c|c|c|c|c|c|c|c|}
\hline \multirow[b]{2}{*}{ Item } & \multicolumn{2}{|c|}{ Early } & \multicolumn{2}{|c|}{ Mid } & \multicolumn{2}{|c|}{ Late } & \multirow[b]{2}{*}{ SEM } & \multicolumn{3}{|c|}{ Test of Effects $(P>\mathrm{F})$} \\
\hline & $\mathrm{C}$ & NF & $\mathrm{C}$ & $\mathrm{NF}$ & $\mathrm{C}$ & $\mathrm{NF}$ & & Diet & Time-day & DIM \\
\hline Pre-feeding leptin & 4.02 & 2.58 & 3.58 & 1.97 & 2.86 & 2.59 & 0.57 & & & \\
\hline Post-feeding leptin & 4.44 & 3.16 & 3.79 & 2.04 & 3.08 & 2.79 & 0.55 & 0.025 & 0.004 & 0.357 \\
\hline DMI, g/BW ${ }^{0.75}$ & 135 & 164 & 126 & 147 & 91 & 95 & 10.2 & 0.022 & & 0.254 \\
\hline
\end{tabular}

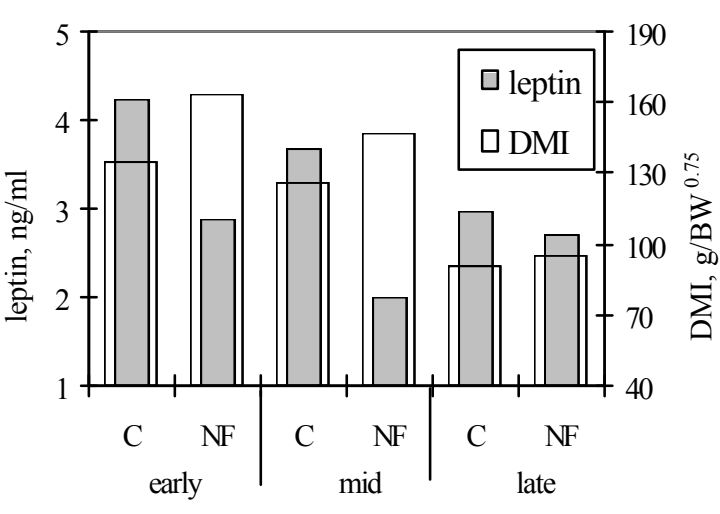

Fig 1 Relationship between plasma leptin and DMI
Conclusions The opposite trend in the pattern of diet effects on DMI and plasma leptin, both in pre- and postfeeding state, induces to retain that in goats throughout lactation the levels of leptin can be related to DM intake, as Barb (1999) proposed in other animal models.

Finally, it is interesting to note that also in lactating goats, as in other species, plasma leptin level increased during the post-feeding phase.

References Barb, C.R. 1999. The brain-pituitaryadipocyte axis: role of leptin in modulating neuroendocrine function. Journal of Animal Science 77:1249-57

Houseknecht, K.L., Baile, C.A., Matteri, R.L., and Spurlock, M.E. 1998. The biology of leptin: a review. Journal of Animal Science 76:1405-1420 